\title{
バイオアベイラビリティの個体差を考慮した 母集団薬物動態解析の有用性評価（3）
}

\author{
小山真澄, 平池 巧, 松浦佳輔, 宇佐美陽平, 橋本征也 ${ }^{*}$ \\ 富山大学大学院医学薬学研究部医薬品安全性学研究室
}

\section{Evaluation of Usefulness of Population Pharmacokinetic Analysis Considering Interindividual Variability of Bioavailability (3)}

\author{
Masumi Koyama, Takumi Hiraike, Keisuke Matsuura, Youhei Usami and Yukiya Hashimoto* \\ Graduate School of Medicine and Pharmaceutical Sciences, University of Toyama \\ $\left[\begin{array}{l}\text { Received August 24, } 2018 \\ \text { Accepted October 14, } 2018\end{array}\right]$
}

We previously reported a positive correlation between the oral clearance (CL/F) and the apparent volume of distribution $(\mathrm{V} / \mathrm{F})$ of drugs with variable bioavailability $(\mathrm{F})$. The aim of the present study using a computer simulation method was to further evaluate the usefulness of the population pharmacokinetic analysis model assuming the

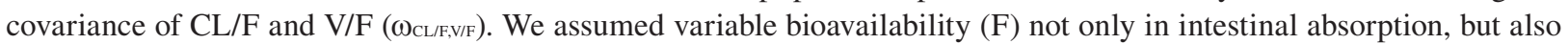
in hepatic first-pass extraction and transdermal absorption. The log likelihood difference (LLD) between the covariance and conventional (non-covariance) model analysis was very similar to the LLD between the true and conventional model analysis. The individual relative $\mathrm{F}\left(\mathrm{F}_{\text {rel }}\right)$ values estimated with the covariance model analysis was also similar to the $\mathrm{F}_{\text {rel }}$ values estimated with the true model analysis. Therefore, we should use the covariance model and/or the true model positively for population pharmacokinetic analysis for drugs with variable F.

\footnotetext{
Key words — covariance model, nonlinear mixed effects model (NONMEM), bioavailability, population pharmacokinetics
}

\section{緒言}

我々はビソプロロールなどの薬物では，消化管 吸収の個体差に伴うバイオアベイラビリティ（F） の変動が, 薬物動態に大きな影響を与えることを 報告してきた. ${ }^{1,2)}$ すなわち, Fig 1 はF の個体差 が経口クリアランス $(\mathrm{CL} / \mathrm{F})$ と見かけの分布容 積（V/F）に与える影響を評価した結果を引用し たものであるが, ${ }^{2)} \mathrm{F}$ に個体差を導入すると CL/F と V/Fには正の相関が認められ, 両者には共分 散 ( $\left.\omega_{\text {CLIF, V/F }}\right)$ が生じるようになる。従って, Fに 個体差が想定される薬物の母集団動態解析に際し ては, $\omega_{\mathrm{CL} / \mathrm{F}, \mathrm{V} / \mathrm{F}}$ を導入した covariance model を用い て， CL/Fと V/F の相関性を考慮することが妥当
であると考えられる. ${ }^{1,2)} し か し ，$ 現段階では covariance model の有用性については, 限られた 知見しかないのが現状である. ${ }^{2,3)}$ そこで本研究で は,コンピュータシミュレーションの手法を用い て CL/Fと V/F の共分散（的L/F, V/F $)$ を仮定した covariance model による母集団薬物動態解析の有 用性の評価を更に推し進めた。

これまでの我々の研究では，ビソプロロールを モデル薬物として選択し, 消化管吸収の不完全性 を仮定して薬物速度論モデルを構築してきた. ${ }^{1-3)}$ すなわち, 薬物の消化管からの急速な吸収を仮定 した1-コンパートメントモデルを専ら用いてき た. ${ }^{1-4)}$ 一方, 本研究の目的の第一は, より多様な $\mathrm{F}$ の変動機構について考察を加え, 複数の薬物速

\footnotetext{
*テ930-0194＼cjkstart富山市杉谷2630
} 


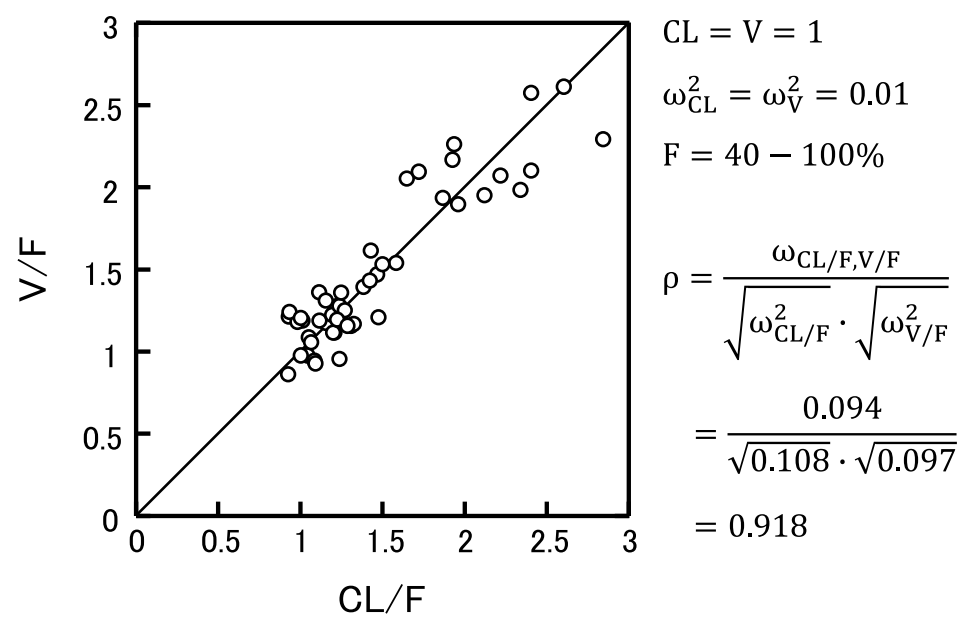

Fig 1 Effect of interindividual variability of bioavailability (F) on oral clearance $(\mathrm{CL} / \mathrm{F})$ and apparent volume of distribution (V/F) of a hypothetical drug ${ }^{2}$

度論モデルを用いて covariance model の有用性を 評価することである。まず，ミゾリビンのように 消化管からの吸収速度がビソプロロールほど速く はないことを想定し, ${ }^{4,5)}$ 不完全な 1 次吸収過程を 導入した1-コンパートメントモデルを用いて検討 を行った，次に，具体的な薬物名は挙げないが, 脂溶性が高く消化管における吸収特性は速く，ほ ぼ完全であるものの, 肝臓における代謝が著しい ために初回通過代謝を受ける薬物を想定した。さ らに本研究では, 薬物が経口投与されるのではな く，経皮吸収製剂を用いて全身循環を介して作用 することを期待する薬物も想定して検討を加えた。

本研究の目的の第二は, covariance modelによ る母集団解析の精度を, 真の解析モデル（true model）によるそれと比較・評価することである. すなわち, 同一被験者に対し静脈内と経口（経皮） 投与試験が行われない限り, $\mathrm{F}$ の平均值とその個 体差を精密に推定することは不可能である。しか し，コンピュータシミュレーションの手法を用い れば，Fの平均值が既知であると仮定し, true model を用いて経口 (経皮) 投与時の血中濃度デー 夕のみから F の個体間変動を推定することが可 能になる。我々はこれまで, covariance model は true model 近似の解析モデルであると考えてきた が, ${ }^{2,3}$ 本研究によって covariance model がどの程度 true model に近似しているかを明らかにしたい.

\section{方 法}

\section{1. 薬物血中濃度データ作成 (シミュレーション) と母集団動態解析}

仮想被験者は，30 名の健常者を想定した。す なわち, 体重（WT）は 40～80（kg）の間に均 一に分布し，クレアチニンクリアランス $\left(\mathrm{CL}_{\mathrm{cr}}\right)$ は $5 \sim 6(\mathrm{~L} / \mathrm{hr})$ の間に均一に分布すると仮定し た．また，薬物動態は1-コンパートメントモデ ルに従うものと仮定し, 以下の 3 種類の $\mathrm{F}$ の変 動機構を想定した。

（1）小腸 1 次吸収過程

小腸の 1 次吸収過程に個体間変動があることを 想定し，以下に示すような平均パラメー夕を用い て, シミュレーションを行った. すなわち, 平均 吸収速度定数 $\left(\mathrm{K}_{\mathrm{a}}\right)$ を $0.8\left(\mathrm{hr}^{-1}\right)$ と仮定し, 全 身クリアランス $(\mathrm{CL})$ は $\mathrm{CL}_{\mathrm{cr}}$ に等しいと仮定した。 平均分布容積 $(\mathrm{V})$ は体重の 0.4 倍であり, $\mathrm{F}$ は 60～100\%の間に均一に分布すると仮定した，投 与量は単回投与で $150 \mathrm{mg}$ とした. $\mathrm{K}_{\mathrm{a}}, \mathrm{CL}, \mathrm{V}$ の

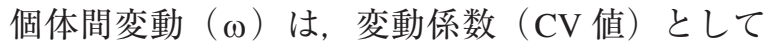
$15 \%$ を仮定し, 血中濃度の個体内変動（ $\sigma$ ）は $7 \%$ と想定した。なお，一様乱数および正規乱数は Microsoft Excel ${ }^{\circledR} 2013$ を用いて発生させた。

Conventional（non-covariance） model を基準と して, true model と covariance model 解析の性能 を評価した。すなわち, conventional model 解析 
では， $\mathrm{K}_{\mathrm{a}}, \mathrm{CL} / \mathrm{F}, \mathrm{V} / \mathrm{F}$ の平均值とそれぞれの分散 $\left(\omega_{\mathrm{Ka}}^{2}, \omega_{\mathrm{CLF}}^{2}, \omega_{\mathrm{VF}}^{2}\right)$ に加え， $\sigma^{2}$ を算出した. True model 解析では, F の平均值を真值に固定し, $\mathrm{K}_{\mathrm{a}}$, $\mathrm{CL}, \mathrm{V}$ の平均值とそれぞれの分散 $\left(\omega_{\mathrm{F}}^{2}, \omega_{\mathrm{Ka}}^{2}, \omega_{\mathrm{cL}}^{2}\right.$, $\left.\omega^{2} \mathrm{v}\right)$ および $\sigma^{2}$ 算出した. Covariance model 解析 では， $\mathrm{K} a, \mathrm{CL} / \mathrm{F}, \mathrm{V} / \mathrm{F}$ の平均值とそれぞれの分散 $\left(\omega_{\mathrm{Ka}}^{2}, \omega_{\mathrm{CLF}}^{2}, \omega_{\mathrm{VFF}}^{2}\right)$ に加え, $\omega_{\mathrm{CLFVFF}}$ と $\sigma^{2}$ 算出した.

母集団解析とそれに引き続くべイジアン個別解 析は, NONMEMソフトウェア (double precision NONMEM Version VI Level 2.0, PREDPP Version V Level 2.0, NM-TRAN Version IV Level 2.0, Beal SL and Sheiner LB, San Francisco, CA, USA）を用いて 行い, ${ }^{6}$ このシミュレーションに対しては NONMEMPREDPP のサブルーチン ADVAN2 と TRANS2 を 使用した。

\section{（2）肝初回通過代謝}

肝臓における初回通過代謝を受ける薬物を想定 し検討を行った。すなわち, 薬物の肝抽出率が 90\%であると仮定し，CL は WT の 1.35 倍である とし，VはWTの 7 倍であるとしたＦは 5 15\% の間に均一に分布すると想定した，投与量は単回 投与で $120 \mathrm{mg}$ とした. CL，Vの $\omega$ は， CV 值と して 15\%を仮定し，。は7\%と想定した.

このシミュレーションの母集団解析には, NONMEM-PREDPP のサブルーチン ADVAN1 と TRANS2 を使用した。 ${ }^{6}$ 上記の方法に準じて, conventional model, true model, covariance model を用いて母集団解析を行い, $\mathrm{K}_{\mathrm{a}}$ と $\omega_{\mathrm{Ka}}^{2}$ 以外のパ ラメーターを算出した

\section{（3）経皮 0次吸収}

経皮吸収製郕を想定し検討を行った。すなわち 平均 CL は WT の 0.3 倍, V はWT の 2 倍と仮定し, Fは 10〜 50\%の間に均一に分布すると考えた。投 与は単回投与のみで, 24 時間貼付することによっ て 0 次で吸収されると仮定し, 投与量は $120 \mathrm{mg}$

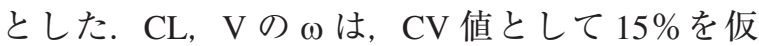
定し，のは7\%と想定した.

このシミュレーションの母集団解析には, 上記 と同様に NONMEM-PREDPP のサブルーチン ADVAN1 と TRANS2 を使用した。

\section{2. 母集団動態解析の性能評価}

(1) log likelihood difference (LLD)

本研究では, conventional (non-covariance) model を基準として, true model と covariance modelによる デー夕適合性の改善度をLLDを用いて評価した. ${ }^{2,3,6)}$ すなわち, NONMEM が算出した目的関数值 $(-2$ log likelihood）を用いて, true model と covariance model の LLD を算出した ${ }^{2,3,6}$ Conventional model に 比ベパラメータ数が 1 つ増加する true model と covariance model $の$ LLD が $3.84(P<0.05)$ もしく は6.64（ $P<0.01 ）$ より大きい時, そのモデルは 統計的に有意であると判定した，また，パラメー 夕数が同じである true model と covariance model の 優位性を, LLD を比較することによって評価した。

(2) 相対的なバイオアベイラビリティ（ $\left.F_{\text {rel }}\right)$

本研究においては，LLDに加えて $F_{\text {rel }}$ を評価指 標として用いた。 ${ }^{2,3)}$ 仮想薬物は静脈投与試験を想 定していないため, 絶対的 $\mathrm{F}$ を推定することは 不可能である。しかし, covariance modelによる 母集団解析後のベイジアン解析で算出した, 各被 験者の $\mathrm{CL} / \mathrm{F}\left(\mathrm{CL} / \mathrm{F}_{\text {Bayes }}\right)$ p $\mathrm{V} / \mathrm{F}\left(\mathrm{V} / \mathrm{F}_{\text {Bayes }}\right)$ から平 均值を 1 とした相対的な $\mathrm{F}$ を推定することは可 能である。すなわち, covariance modelにおいて $\mathrm{F}_{\text {rel }}$ は母集団平均の $\mathrm{CL} / \mathrm{F}_{\text {mean }}$ (または $\mathrm{V} / \mathrm{F}_{\text {mean }}$ ）を各 個人の $\mathrm{CL} / \mathrm{F}_{\text {Bayes }}\left(\right.$ または $\left.\mathrm{V} / \mathrm{F}_{\text {Bayes }}\right)$ で除することに よって得られると仮定し, 次のような式を用いて 算出した。

$$
\begin{aligned}
& F_{\text {rel }}=\frac{\mathrm{CL} / F_{\text {mean }}}{\mathrm{CL} / \mathrm{F}_{\text {Bayes }}} \\
& F_{\text {rel }}=\frac{\mathrm{V} / F_{\text {mean }}}{\mathrm{V} / \mathrm{F}_{\text {Bayes }}}
\end{aligned}
$$

本研究においては, 式(1)および式(2)から求めた $\mathrm{F}_{\mathrm{rel}}$ の平均值を用いた。

True model では母集団解析後のベイジアン解析 によって各個人の F の絶対值が得られるが, covariance model と比較するため $\mathrm{F}_{\mathrm{rel}}$ に換算した. すなわち, true modelにおいてはべイジアン解析 によって求められた各被験者の $\mathrm{F}\left(\mathrm{F}_{\text {Bayes }}\right)$ を平均 值 $\left(\mathrm{F}_{\text {mean }}\right)$ によって除することにより得られると 仮定し，以下の式を用いて算出した.

$$
\mathrm{F}_{\text {rel }}=\frac{\mathrm{F}_{\text {Bayes }}}{\mathrm{F}_{\text {mean }}}
$$


また， $F_{\mathrm{rel}}$ の推定精度を定量化するために\% error を次のようにして計算した. ${ }^{2,3)}$

$$
\% \text { error }=(\text { 推定値 }- \text { 真値 }) \div \text { 真值 } \times 100
$$

この\% errorの平均值は偏りの度合を表し，0に 近いほど $\mathrm{F}_{\mathrm{rel}}$ の推定值が正確であることを示す. また, \% errorの標準偏差は $\mathrm{F}_{\mathrm{rel}}$ の推定精度を表し， 值が小さいほど精度が高いことを示す.

\section{結＼cjkstart果}

\section{1. 小腸 1 次吸収過程}

小腸で不完全に 1 次吸収される薬物を想定しシ ミュレーションを行った。単回投与における血中 濃度推移を Fig 2A に示す. 採血は薬物投与から 1, $2,3,4,6,8,12,24$ 時間後の 8 点で行う臨床 試験を想定した。血中濃度の個体内変動（ $\sigma ）$ は
$\mathrm{CV}$ 值で 7\%としたため, 各被験者の血中薬物濃 度推移には不自然な上下動が認められる場合も あった（Fig 2A）。この模擬臨床試験のデー夕を conventional model, true model, covariance model で 解析し, true model と covariance model の解析精 度を比較した（Fig 3). Figure 3A には true model の解析結果を示しているが, conventional model 解析との LLD 值は 29.949 であり, 統計的に有意 $(P$ く0.01）であった，また，その時に推定した各被 験者の $\mathrm{F}_{\mathrm{rel}}$ は真值 $\left(\mathrm{F}_{\text {rel-true }}\right)$ との間に無難な対応が 認められ，\% errorの值は $0.60 \pm 11.30$ であった。

一方, Fig 3B に covariance model での解析結果 を示す. Convention model 解析との LLD 值は covariance model では29.949であり, true model の LLD 值と同じ值であった. Covariance model に よる $\mathrm{F}_{\mathrm{rel}}$ の推定も true model と大差はなく, $\mathrm{F}_{\text {rel-true }}$ との間に無難な対応が認められ，\% errorの值は
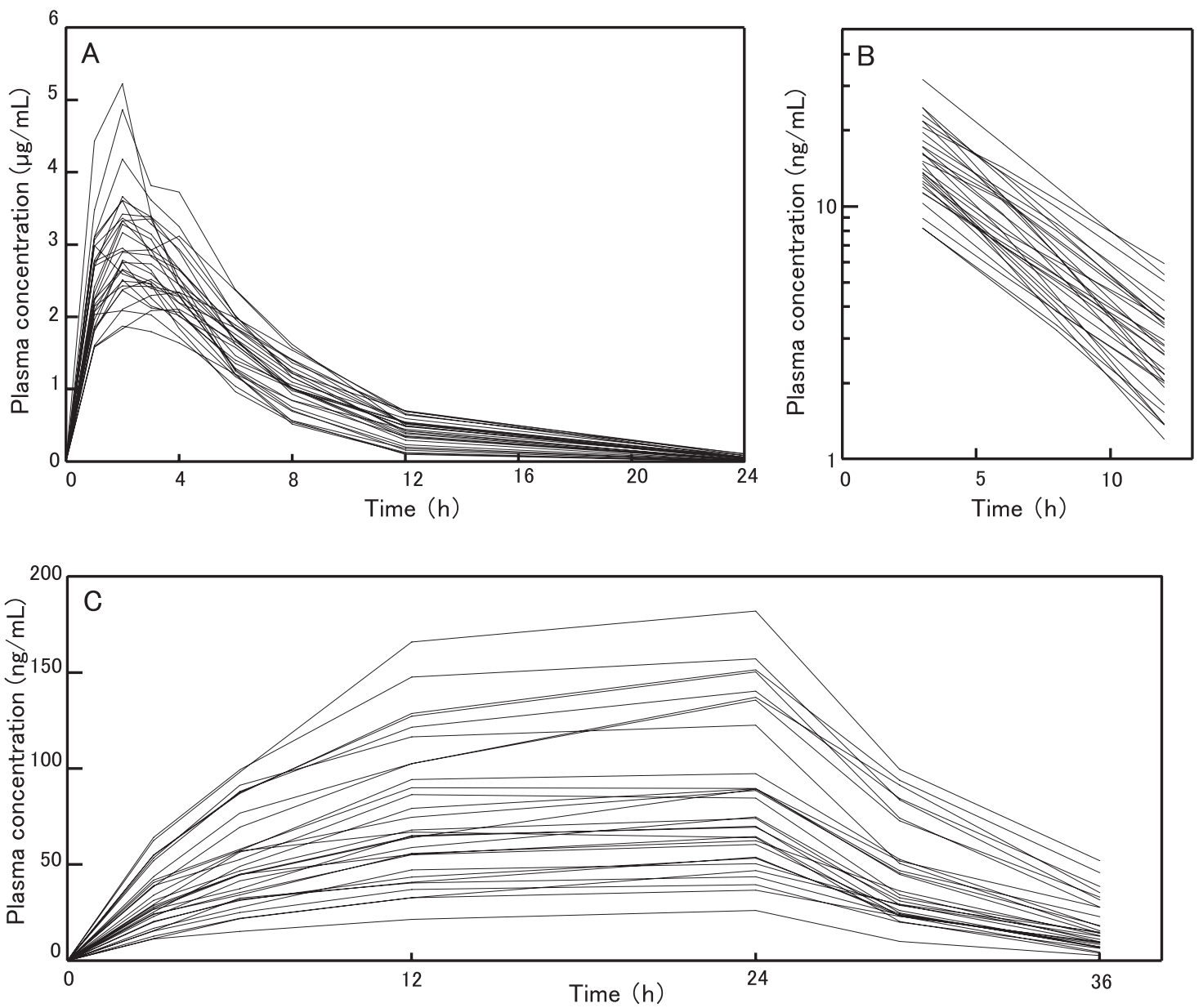

Fig 2 Plasma concentrations of 3 hypothetical drugs (A-C)

A: Intestinal 1-st order absorption, B: Hepatic first-pass extraction, C: transdermal zero-th order absorption. 

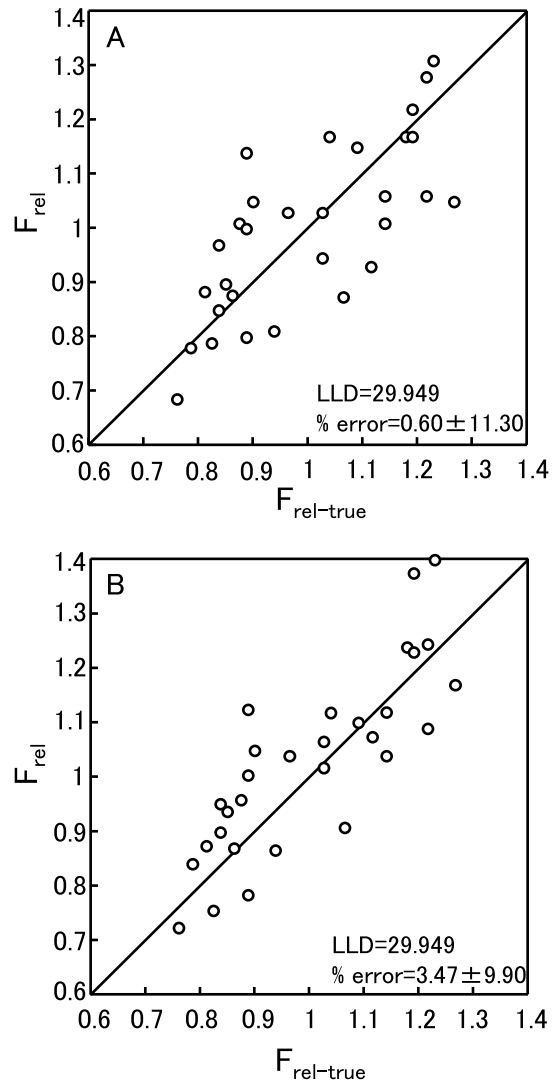

Fig 3 Relative bioavailability $\left(\mathrm{F}_{\mathrm{rel}}\right)$ estimated with true model analysis (A) and covariance model analysis (B) for a hypothetical drug with 1-st order intestinal absorption

The regression line is $\mathrm{y}=\mathrm{x}$. LLD: log likelihood difference.

$3.47 \pm 9.90$ であった。 このシミュレーションで はF 占 60\%から 100\%まで変動すると仮定して いるので, $\mathrm{F}_{\text {rel-true }}$ の上限と下限はそれぞれ 1.25 （100/80）と0.75（60/80）であるが, covariance model による $\mathrm{F}_{\mathrm{rel}}$ の推定值は約 0.71〜1.40 に分布 すると算出され，大きな乘離はなかった。

\section{2. 肝初回通過代謝}

肝臓で初回通過代謝される薬物を想定しシミュ レーションを行った，単回投与に扔ける血中濃度 推移を Fig 2B に示す. 薬物投与から 3，6，12 時 間後または $3 ， 8 ， 12$ 時間後の 3 点で採血を行うと 想定した。Fが $5 \%$ から $15 \%$ と個人間で 3 倍変動 すると仮定したため, 各患者間の血中濃度には Fig 2Bに見られるように大きなばらつきが観察された。 この試験のシミュレーションを上記と同様に 3 種 のモデルで解析した. Figure 4A には true model の
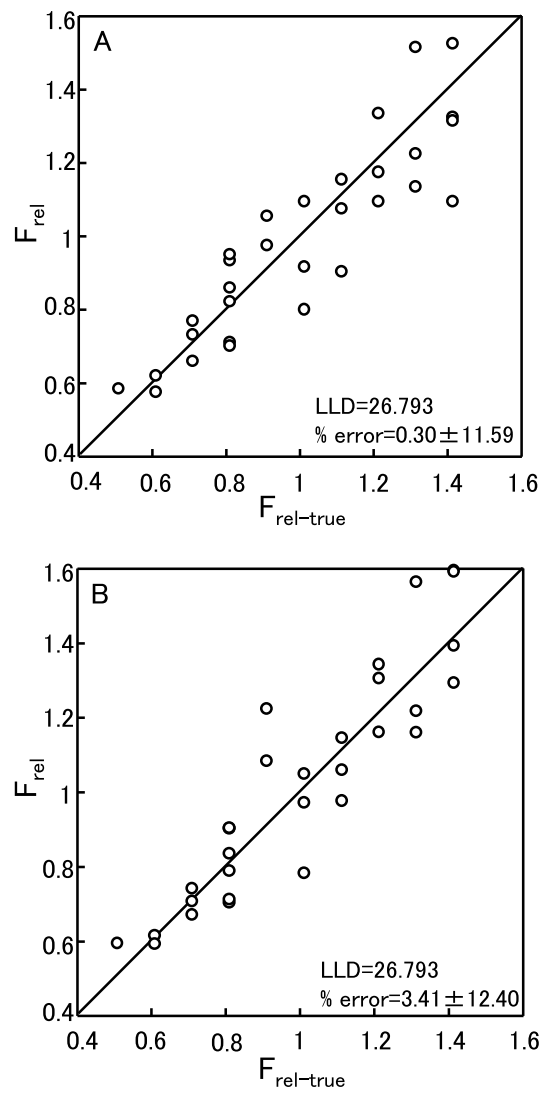

Fig 4 Relative bioavailability $\left(\mathrm{F}_{\mathrm{rel}}\right)$ estimated with true model analysis (A) and covariance model analysis (B) for a hypothetical drug with extensive hepatic first-pass extraction

The regression line is $\mathrm{y}=\mathrm{x}$. LLD: $\log$ likelihood difference.

解析結果を, Fig 4B には covariance model の解析 結果を示す. True model の LLD 值は 26.793であり, covariance model の LLD 值も同じく26.793であった. このシミュレーションでは, Fが5\%から 15\%まで変 動すると仮定したので， $F_{\text {rel-true }}$ の上限と下限はそれぞ れ $1.5 （ 15 / 10 ）$ と $0.5 （ 5 / 10)$ であるが, true model および covariance model による $\mathrm{F}_{\mathrm{rel}}$ の推定值の分布 にあまり大きな乘離は認められなかった（Fig 4).

\section{3. 経皮O次吸収}

経皮吸収製剤を想定しシミュレーションを行っ た．単回投与における血中濃度推移を Fig $2 \mathrm{C}$ に 示す。薬剤は 24 時間貼付するものとし, 薬剤貼 付後から $3,6,12,24$ 時間後, 薬剤除去後 5 , 12 時間後の計 6 点の採血を行う試験を想定した. Fが 10\%から 50\%まで変動すると仮定したため, 患者間の血中濃度推移には大きなばらつきが観察 

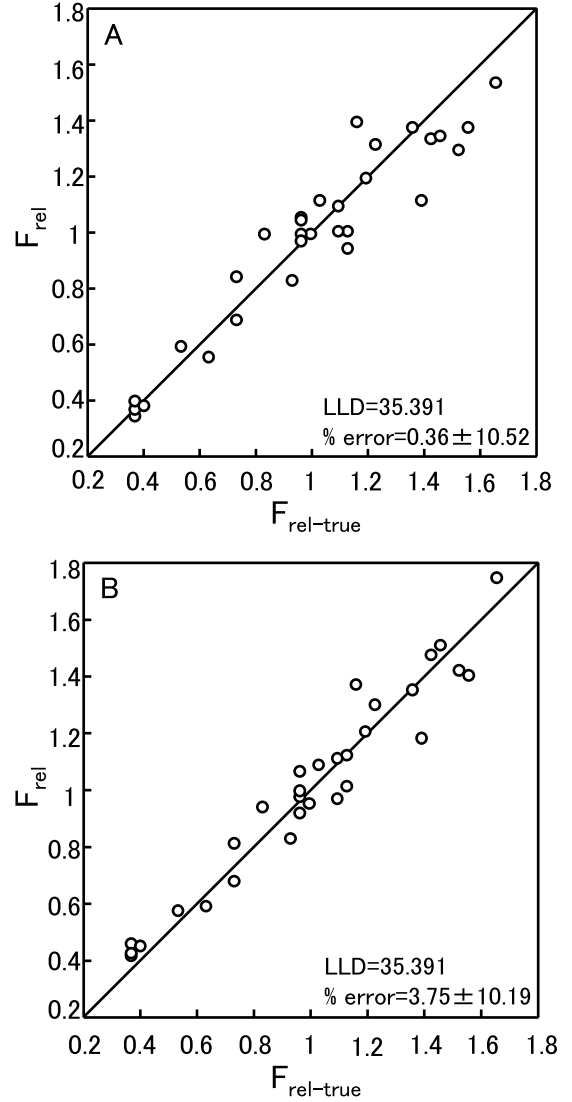

Fig 5 Relative bioavailability $\left(\mathrm{F}_{\text {rel }}\right)$ estimated with true model analysis (A) and covariance model analysis (B) for a hypothetical drug with transdermal zeroth order absorption

The regression line is $\mathrm{y}=\mathrm{x}$. LLD: $\log$ likelihood difference.

された。この試験のシミュレーションを上記と同 様に 3 種のモデルで解析した. Figure 5A には true model の解析結果を, Fig 5B には covariance model の解析結果を示す。 True model の LLD 值は 35.391 であり, covariance model の LLD 值も同じく 35.391 であったこのシミュレーションでは，Fが10\%か ら 50\%まで変動すると仮定したので， $F_{\text {rel-true }}$ の上限

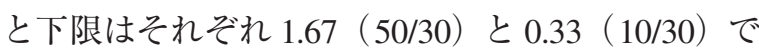
あるが, true model および covariance modelによる $\mathrm{F}_{\mathrm{rel}}$ の推定值の分布にほとんど乘離は認められな かったことから， $F_{\text {rel }}$ は薬物の $\mathrm{F} の$ 変動域（範囲） を考察する上で有用であると考えられた（Fig 5).

\section{考察}

本研究では, 不完全な消化管からの 1 次吸収, 急速な消化管吸収後の肝初回通過代謝, 経皮 0 次
吸収を受ける薬物を想定した $($ Fig 1, 2). シミュ レーションした血中濃度を, conventional（noncovariance) model, true model, covariance model 用いて母集団解析を行った (Fig 3-5). Conventional model の最小目的関数值（-2 log likelihood）を基 準として, true model と covariance model の LLD 值を算出したところ, 不完全な消化管からの 1 次 吸収, 急速な消化管吸収後の肝初回通過代謝, 経 皮 0 次吸収を受ける薬物のいずれにおいても true model と covariance model の LLD 值は等しくなっ た（Fig 3-5）。このことより covariance model は, true model と同等であると見做して良いと考えら れた。

なお，詳細な結果は示していないが，不完全な 消化管からの 1 次吸収を受ける薬物を 8 時間毎に 繰り返し投与した際の母集団解析結果でも, true model と covariance model の LLD 值は等しくなっ た.さらに，急速な消化管吸収後に肝初回通過代 謝を受ける薬物を 12 時間毎に繰り返し投与した 際の母集団解析結果でも, true model と covariance model の LLD 值は等しくなったことを付け加え ておきたい.

本研究では, true model および covariance model による母集団解析を行った後に, ベイジアン個別 解析で, 平均值を 1 とした相対的なバイオアベイ ラビリティ $\left(\mathrm{F}_{\mathrm{rel}}\right)$ を算出した. $\mathrm{F}$ の個体差が大き くなるに従って， $\mathrm{F}_{\mathrm{rel}}$ の個体差も大きくなることか ら， $\mathrm{F}_{\mathrm{rel}}$ の算出は $\mathrm{F}$ の変動性を類推するうえで有用 な可能性がある（Fig 3-5）. Covariance model によ る $\mathrm{F}_{\mathrm{rel}}$ の\% error の平均值は, 僅かに（3.5\% 程度） 正方向に偏っているかもしれないが, その標準偏 差は true model とほぼ同程度であった（Fig 3-5）。

本シミュレーション研究では, true model を使 用する際に， $\mathrm{F}$ の平均值が既知であると仮定して 母集団解析を行い covariance model と比較・評価 した，しかし，現実には経口（経皮）製剤の Fの 平均值が正確にわかっている場合は有り得ない. 従って, true model を用いて母集団解析を行う際 には, $\mathrm{F}$ の平均值を任意の值（または近似值）に 固定し, 解析を進めることになるであろう. ${ }^{7} し$ かし, 我々が知る限り, Fの個体差まで考慮した true model による臨床デー夕解析は皆無であり, ${ }^{7}$ 
本研究以外の速度論モデルや臨床試験デザインに 対する true model の性能は不明である. 従って, true model を用いて臨床デー夕解析を行うに際し ては, covariance model を併用するなど慎重を期 するべきであろう。

以上本研究では, 経口（経皮）投与後の血中濃 度デー夕に対する, covariance model 解析の性能 評価を追加した，今後，より多様な薬物について covariance model（または true model）が臨床応用 され，F の個体差に関する情報が整備されること が期待される。

\section{利益相反}

開示すべき利益相反はない.

\section{引用文献}

1) Ishida K, Horie A, Nishimura M, Taguchi M, Fujii N, Nozawa T, Inoue H, Hashimoto Y, Variability of bioavailability and intestinal absorption characteristics of bisoprolol, Drug Metab Pharmacokinet, 2013, 28, 491-496

2）松葉映美, 服部龍太郎, 大久保翔悟, 深尾美紀,
橋本征也, バイオアベイラビリティの個体差を 考慮した母集団薬物動態解析の有用性評価, 医 療薬学, 2016, 42, 408-415.

3）松葉映美, 宇佐美陽平, 服部龍太郎, 深尾美紀, 橋本征也, バイオアベイラビリティの個体差を 考慮した母集団薬物動態解析の有用性評価（2）, 医療薬学, 2016, 42, 809-816.

4) Fukao M, Ishida K, Sakamoto T, Taguchi M, Matsukura H, Miyawaki T, Hashimoto Y, Effect of genetic polymorphisms of SLC28A1, ABCG2 and ABCC4 on bioavailability of mizoribine in healthy Japanese males, Drug Metab Pharmacokinet, 2011, 26, 538-543.

5) Ishida K, Motoyama O, Shishido S, Tsuzuki K, Hashimoto Y, Population pharmacokinetics of mizoribine in pediatric recipients of renal transplantation, Clin Exp Nephrol, 2012, 16, 799-804.

6) Beal SL, Boeckmann AJ, Sheiner LB, "NONMEM Users Guides: NONMEM Project Group” University of California, San Francisco, 1992.

7）堀了平, 宮崎勝已, 水柿道直, 緒方弘泰, 後藤 光良, 市村藤雄, 安原眞人, 谷川原祐介, 橋本征也, 小上淑子, 三牧孝至, 田中一彦, 奥村勝彦, 五味田 裕, 樋口 駿. 日本人における薬物動態母集団 パラメータの推定 (1) : ジゴキシン, TDM 研究, 1994, 11, 7-17. 